\title{
Neutron and X-ray diffraction and empirical potential structure refinement modelling of magnesium stabilised amorphous calcium carbonate
}

\author{
G. Cobourne ${ }^{\text {a }}$, G. Mountjoy ${ }^{\text {a,* }}$, J.D. Rodriguez-Blanco ${ }^{\text {b,c }}$, L.G. Benning ${ }^{\text {b }}$, A.C. Hannon ${ }^{\text {d }}$, J.R. Plaisier ${ }^{e}$ \\ a School of Physical Sciences, University of Kent, Ingram Building, Canterbury CT2 7NH, UK \\ b School of Earth and Environment, University of Leeds, Leeds LS2, 9JT, UK \\ ' Department of Chemistry, University of Copenhagen, Universitetsparken 5, 2300 Copenhagen, Denmark \\ d ISIS Facility, Rutherford Appleton Laboratory, Chilton, Didcot OX11 0QX, UK \\ e Elettra Sincrotrone Trieste S.C.p.A., Strada Statale 14, km 163.5, 34149 Basovizza, Ts Italy
}

\section{A R T I C L E I N F O}

\section{Article history:}

Received 3 October 2013

Received in revised form 15 December 2013

Available online $\mathrm{xxxx}$

\section{Keywords:}

Amorphous calcium carbonate;

EPSR modelling:

Neutron diffraction;

X-ray diffraction

\begin{abstract}
A B S T R A C T
Amorphous calcium carbonate (ACC) plays a key role in biomineralisation processes in sea organisms. Neutron and X-ray diffraction have been performed for a sample of magnesium-stabilised ACC, which was prepared with a Mg:Ca ratio of 0.05:1 and $0.25 \mathrm{H}_{2} \mathrm{O}$ molecules per molecule of $\mathrm{CO}_{3}$. The empirical potential structure refinement method has been used to make a model of magnesium-stabilised ACC and the results revealed a fair agreement with the experimental diffraction data. The model has well-defined $\mathrm{CO}_{3}$ and $\mathrm{H}_{2} \mathrm{O}$ molecules. The average coordination number of $\mathrm{Ca}$ is 7.4 and is composed of 6.8 oxygen atoms from $\mathrm{CO}_{3}$ molecules and 0.6 oxygen atoms from $\mathrm{H}_{2} \mathrm{O}$ molecules. The average $\mathrm{Ca}-\mathrm{O}$ bond length is $2.40 \AA$. The distribution of $\mathrm{Ca}$ in the model is homogeneous with a uniformly distributed Ca-rich network and no evidence of the Ca-poor channels as previously reported for a reverse Monte Carlo model of ACC.
\end{abstract}

(C) 2013 Elsevier B.V. All rights reserved.

\section{Introduction}

Amorphous calcium carbonate (ACC) is believed to play a key role in biomineralisation processes within organisms, including sea urchins, crustaceans and sea shells (Bivalvia) [1], which use the crystalline calcium carbonate(s) as structural building blocks. Most notably, ACC has been proposed to be the form of calcium carbonate prior to its crystallisation to aragonite or calcite to form new structural elements of the organism [1]. ACC may thus have an analogous role to the mammalian equivalent, amorphous calcium phosphate (ACP), which is involved in biomineralisation of crystalline calcium phosphates within human bones [2].

Greater understanding of biomineralisation processes should include detailed knowledge of the atomic structure of all calcium carbonate phases, including ACC, and of the mechanisms and pathways of crystallisation of ACC in biomineralisation processes, as well as the relation between ACC and the structures of crystalline calcium carbonate phases. The composition of ACC has been reported as $\mathrm{CaCO}_{3} \cdot \mathrm{nH}_{2} \mathrm{O}$ where $n=1-1.6$ [3-6]. The variation in water content, $n$, is related to the process by which ACC is obtained from a calcium source and two common reactants for carbonate ions are $\mathrm{CO}_{2}$ gas molecules and

\footnotetext{
* Corresponding author. Tel.: + 441227 823228; fax: + 441227827558. E-mail address: g.mountjoy@kent.ac.uk (G. Mountjoy).
}

carbonate ions in solution. Furthermore, ACC water content depends on the presence of impurities and on ageing. It is known that ACC dehydrates with time before transforming to crystalline $\mathrm{CaCO}_{3}$, and that this dehydration is faster with increasing temperature and slower with increasing Mg content [4,7-9]. The composition of ACC phases is thus similar to that of monohydrocalcite $\mathrm{CaCO}_{3} \cdot \mathrm{H}_{2} \mathrm{O}$. At ambient temperature, pure ACC is less stable than any of the crystalline polymorphs of calcium carbonate $\mathrm{CaCO}_{3}$ (i.e. calcite, aragonite, vaterite, monohydrocalcite and ikaite) and rapidly crystallises upon dehydration, typically within 2 min in aqueous solution and in less than 1 day at room temperature in air, to either vaterite or calcite [8-10] (the crystallisation to aragonite does not occur at ambient temperatures in a pure system).

Although the term amorphous calcium carbonate has been used for approximately a century [11] it remains to be presented a comprehensive set of structural data and corresponding structural model for an ACC phase. Structural characterisation of ACC using infrared and Raman spectroscopy are frequently reported [e.g. 12,13] but are difficult to interpret in terms of disordered atomic structures. X-ray absorption spectroscopy has provided the most direct probe of $\mathrm{Ca}$ in ACC phases, and $\mathrm{a} \mathrm{Ca}-\mathrm{O}$ bond length of $2.40 \AA$ and a $\mathrm{Ca}-\mathrm{O}$ coordination number of approximately 6 is typically reported [14]. A key experimental technique for studying the atomic structure of amorphous materials is diffraction over a large angular range of scattering sufficient to obtain information about the pair distribution function [15]. However, such diffraction studies of ACC have been limited due to its inherent 
instability. Notably there was a high energy X-ray diffraction study of two types of ACC reported by Michel et al. in 2008 [3] that was used for reverse Monte Carlo (RMC) modelling by Goodwin et al. in 2010 [16]. The RMC study reported that the same results were obtained for two different starting configurations: a disordered monohydrocalcite model (i.e. $\mathrm{n}=1$ ), and a random model containing the same molecular units. The RMC model obtained for ACC was reported to have a calcium rich network (referring to $\mathrm{Ca}-\mathrm{O}-\mathrm{Ca}$ linkages) and $\mathrm{Ca}$-poor channels (regions more than $4 \AA$ A away from a calcium atom). In addition, a recent study of the structure of ACC [17] combined ${ }^{43} \mathrm{Ca}$ NMR measurements and molecular dynamics (MD) modelling and used the Goodwin et al. (2010) model as a starting point, and found that the Ca-rich and Capoor channels proposed by Goodwin et al. (2010) undergo "significant structural reorganization" and "shrink in size" during the 2 ns MD simulation.

One way to facilitate diffraction studies is to work with more stable forms of ACC, which allow more time consuming experiments to be performed, particularly neutron diffraction. The use of both neutron and X-ray diffraction provides important complementary information due to the different atomic scattering for neutrons and X-rays. It has been reported that ACC can be stabilised with various additives such as magnesium [18-20,25], phosphate [19], and poly(aspartic acid) [19]. The present study is focused on Mg-stabilised ACC. The addition of a very small amount of magnesium greatly increases the lifetime of ACC. The most likely cause is the high dehydration energy of the $\mathrm{Mg}^{2+}$-aquo ion compared to the $\mathrm{Ca}^{2+}$ ion [21] that would slow down the dehydration dynamics of ACC [20]. Another benefit of adding magnesium is the smaller size of the Mg ion compared to other ions and thus the Mg ions should have a minor effect on the structure of "pure" ACC. The use of Mg stabilised ACC has made it possible to measure neutron and X-ray diffraction data which are reported here for the first time.

Modelling of diffraction data is also a key technique in the study of amorphous materials. The empirical potential structure refinement (EPSR) method [22] was specifically developed for modelling the structure of molecular liquids [23], but it is also applicable to amorphous solids with molecular units, such as ACC. The EPSR method has some similar features to RMC [24]. EPSR is similar to RMC in that it uses a Monte Carlo method which samples different structures against an "acceptance" criterion, but unlike RMC, the acceptance criteria is the energy minimum based on the inter-atomic potentials. EPSR is like RMC in using the diffraction data to guide the modelling process, but unlike RMC, the difference between the simulated and experimental diffraction is used to adjust the inter-atomic potential. The present study reports a new EPSR model of Mg-stabilised ACC. Some features of this model are found to be different to the previously reported RMC model of ACC [16].

\section{Method}

\subsection{Sample preparation}

Magnesium stabilised ACC (Mg-ACC) was synthesised using the following method based on Rodriguez-Blanco et al. [25] and Jiang et al. [18]. $100 \mathrm{mM}$ solutions of $\mathrm{CaCl}_{2}$ and $\mathrm{Na}_{2} \mathrm{CO}_{3}$ were prepared. $1 \mathrm{~mL}$ of a $500 \mathrm{mM}$ solution of $\mathrm{MgCl}_{2}$ was added to $5 \mathrm{~mL}$ of the $\mathrm{CaCl}_{2}$ solution and this was then rapidly mixed with $5 \mathrm{~mL}$ of the $\mathrm{Na}_{2} \mathrm{CO}_{3}$ solution (to give an ion ratio of $1: 1: 1 \mathrm{Ca}: \mathrm{Mg}: \mathrm{CO}_{3}$ ). This mixing produced a white precipitate which was then rapidly filtered and washed with isopropanol and dried in flowing air [25].

The precipitate was found to have a Mg:Ca ratio of 0.05:0.95 as determined by X-ray fluorescence. The precipitate was further dried and heat-treated for $1 \mathrm{~h}$ at $150{ }^{\circ} \mathrm{C}$ to reduce the water content. Thermogravimetric and differential thermal analyses showed weight losses of $18 \%$ and $21 \%$ up to temperatures of $150{ }^{\circ} \mathrm{C}$ and $350{ }^{\circ} \mathrm{C}$ respectively, the latter being when calcite crystallises. These weight losses are consistent with a water content of $n=1.45$ before and $n=0.25$ after heat treatment at $150{ }^{\circ} \mathrm{C}$. This reduction of water content is important for neutron diffraction because it reduces the detrimental effects of inelastic and incoherent scattering from protons. The heat-treated sample, denoted Mg-ACC, was confirmed amorphous by lab-based powder $\mathrm{X}$-ray diffraction and to remain amorphous for a period of at least two weeks. The density of Mg-ACC after heat treatment was measured to be $2.19 \mathrm{~g} / \mathrm{cm}^{3}$ using a He pycnometer. Note that the above parameters differ from the parameters $\mathrm{n}=1.0$ and density of $2.43 \mathrm{~g} / \mathrm{cm}^{3}$ reported for ACC in Ref. [16], which were taken to be equal to those in crystalline monohydrocalcite.

\subsection{Neutron diffraction}

Neutron diffraction data were measured using the Small Angle Neutron Diffractometer for Liquids and Amorphous Samples (SANDALS) [26] at the ISIS pulsed neutron source, UK. The sample was produced $24 \mathrm{~h}$ before measurement and sealed until it was loaded into a flat plate sample holder with 25 micron thick vanadium plates that were $4 \mathrm{~mm}$ apart. The sample holder was sealed and maintained at a temperature of $5{ }^{\circ} \mathrm{C}$ during the experiment. Time-of-flight data were collected over a wide range of momentum transfer, $\mathrm{Q}$, with a useful maximum of $30 \AA^{-1}$ (where $Q=4 \pi \sin \theta / \lambda$ ). Experimental corrections of the data were performed using the Gudrun program [27]. The SANDALS diffractometer has a forward scattering geometry, which helps reduce the severity of the inelasticity correction, which can be problematic for samples containing hydrogen [26]. There remained a background contribution due to inelastic scattering from $\mathrm{H}$, and this is removed by EPSR (using a back Fourier transform of the part of the real space data in the region $\mathrm{r}<1.5 \AA$ ). The structure factor $\mathrm{S}(\mathrm{Q})$ from neutron diffraction is shown in Fig. 1, including a factor of $\bar{b}^{2}$ (where $\bar{b}$ is the average coherent neutron scattering length).
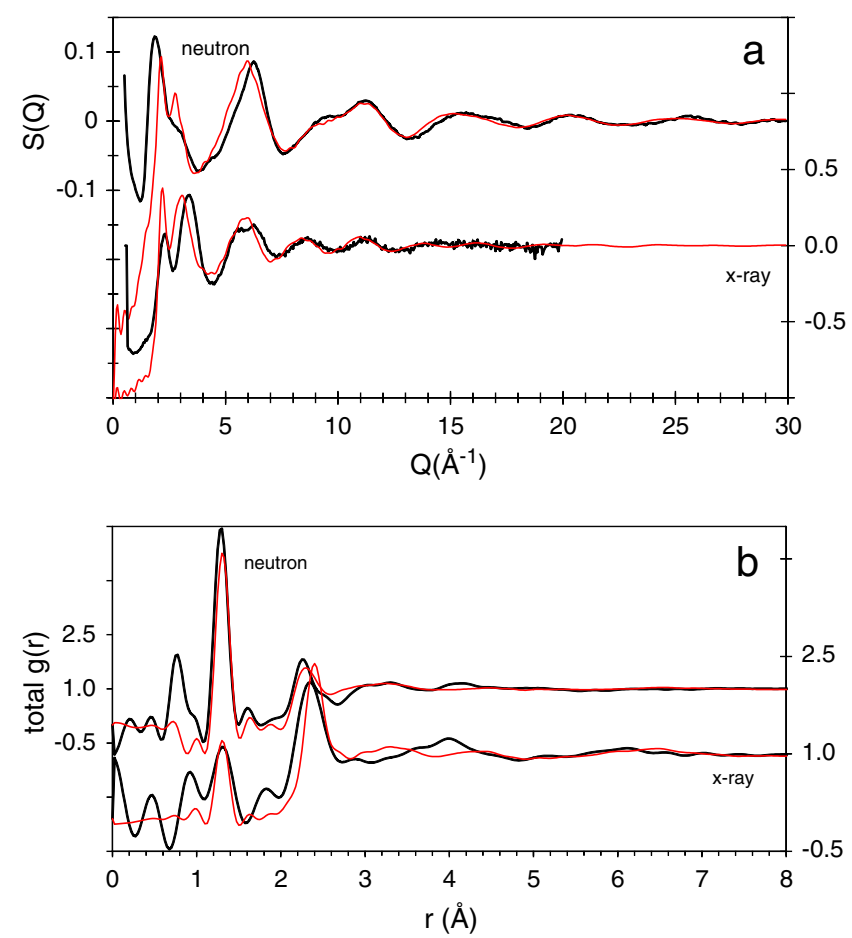

Fig. 1. (a) Experimental structure factors $\mathrm{S}(\mathrm{Q})$ of $\mathrm{Mg}$-stabilised ACC (black lines) for neutron and X-ray diffraction together with the simulated functions (red lines) for the EPSR model (note $S(Q)$ for neutron diffraction includes the factor $\bar{b}^{2}$ in barns per steradian). (b) Total pair distribution functions $\mathrm{g}(\mathrm{r})$. (For interpretation of the references to colour in this figure legend, the reader is referred to the web version of this article.) 


\subsection{X-ray diffraction}

X-ray diffraction data were collected at the MCX beamline [28] at the ELETTRA synchrotron, Italy, using a wavelength of $\lambda=0.620 \AA$. The sample was produced 2 days before travelling to the synchrotron and sealed until it was loaded into a 10 -micron thick $1.0 \mathrm{~mm}$ diameter borosilicate glass capillary. The capillary was rotated at $180 \mathrm{rpm}$ during the experiment. X-ray diffraction data were collected up to $2 \theta$ of $162^{\circ}$ or $\mathrm{Q}=20 \AA^{-1}$. The processing of the raw data included corrections for the background scattering, polarization, sample thickness, absorption, capillary, Compton scattering, and the sharpening function (equal to the square of the average form factor per atom) [15]. The structure factor $S(Q)$ from X-ray diffraction is shown in Fig. 1.

\subsection{Empirical potential structural refinement modelling}

Empirical potential structure refinement (EPSR) $[22,29]$ is a suitable method for generating and refining models of amorphous structures based on molecular units. The present study used the EPSR18 package. Structurally realistic molecular units were initially constructed using GHEMICAL4.0 software [30]. A cubic box with length $\mathrm{L}=39.55$ A containing $950 \mathrm{Ca}, 50 \mathrm{Mg}, 1000 \mathrm{CO}_{3}$ and $250 \mathrm{H}_{2} \mathrm{O}$ units (total 5750 atoms) was assembled using the EPSR shell. This model corresponds to the measured density for Mg-ACC of $2.19 \mathrm{~g} / \mathrm{cm}^{3}$. The density and $\mathrm{H}_{2} \mathrm{O}$ content was based on experimental data as discussed in Section 2.1, and the effect on EPSR results of varying these parameters was not explored. The molecules were randomly translated so they move apart throughout the box. To further separate the molecules, the molecules were randomly rotated and translated 10,000 times.

The EPSR procedure initially relaxed the random starting configuration to an energy minimised structure using a simulated annealing approach with a sequence of temperatures: $10,000 \mathrm{~K}, 5000 \mathrm{~K}, 1000 \mathrm{~K}$, $500 \mathrm{~K}$ and $300 \mathrm{~K}$. At each temperature EPSR carries out Monte Carlo sampling of structures until reaching an equilibrium minimum energy. Starting inter-molecular potentials for each inter-atomic pair correlation $\mathrm{i}-\mathrm{j}$ were generated by EPSR using built-in parameters for Lennard-Jones potentials for each pair of elements. Coulomb interactions are included with formal charges for ions.

The potential refinement was then implemented within the EPSR. The difference between the simulated and experimental neutron and $\mathrm{X}$-ray diffraction data are used to adjust the inter-atomic potentials. The comparison between simulation and experiment is carried out using the structure factors $S(Q)$ (see Fig. 1). The adjusted potentials are then used for a new Monte Carlo sample of structures until reaching equilibrium minimum energy. This process was iterated 20,000 times.

\section{Results}

The final level of agreement obtained between simulated and experimental diffraction data is shown in Fig. 1. The model obtained is shown in Fig. 2. The partial pair distribution functions (PDFs) $g_{i j}(r)$ have been calculated from the model. Fig. 3 shows the PDFs involving $\mathrm{CO}_{3}$ and $\mathrm{H}_{2} \mathrm{O}$ molecules respectively. The continuous lines show intramolecular correlations, and the dashed lines show inter-molecular correlations. The first four peaks in the intra-molecular PDFs (solid lines) represent the internal structure of the molecules: $\mathrm{O}-\mathrm{H}$ and $\mathrm{H}-\mathrm{H}$ distances in $\mathrm{H}_{2} \mathrm{O}$, and $\mathrm{C}-\mathrm{O}$ and $\mathrm{O}-\mathrm{O}$ distances in $\mathrm{CO}_{3}$. The intermolecular PDFs (dashed lines) show $\mathrm{H}$...H and H...O correlations between $\mathrm{H}_{2} \mathrm{O}$ (light dashed), and $\mathrm{C}$... $\mathrm{O}$ and $\mathrm{O}$... O correlations between all molecules (heavy dashed). These correlations and their peak distances are summarised in Table 1.

Fig. 4 shows the PDFs involving Ca. Most prominent are the $\mathrm{Ca}-\mathrm{O}$ distances due to $\mathrm{Ca}$ bonding to the oxygen atoms which are present in $\mathrm{CO}_{3}$ and $\mathrm{H}_{2} \mathrm{O}$ molecules, where the peak distance is $2.40 \AA$. The derived average coordination number of $\mathrm{Ca}$ is 7.4 which is composed of 6.8 oxygen atoms from $\mathrm{CO}_{3}$ molecules and 0.6 oxygen atoms from $\mathrm{H}_{2} \mathrm{O}$

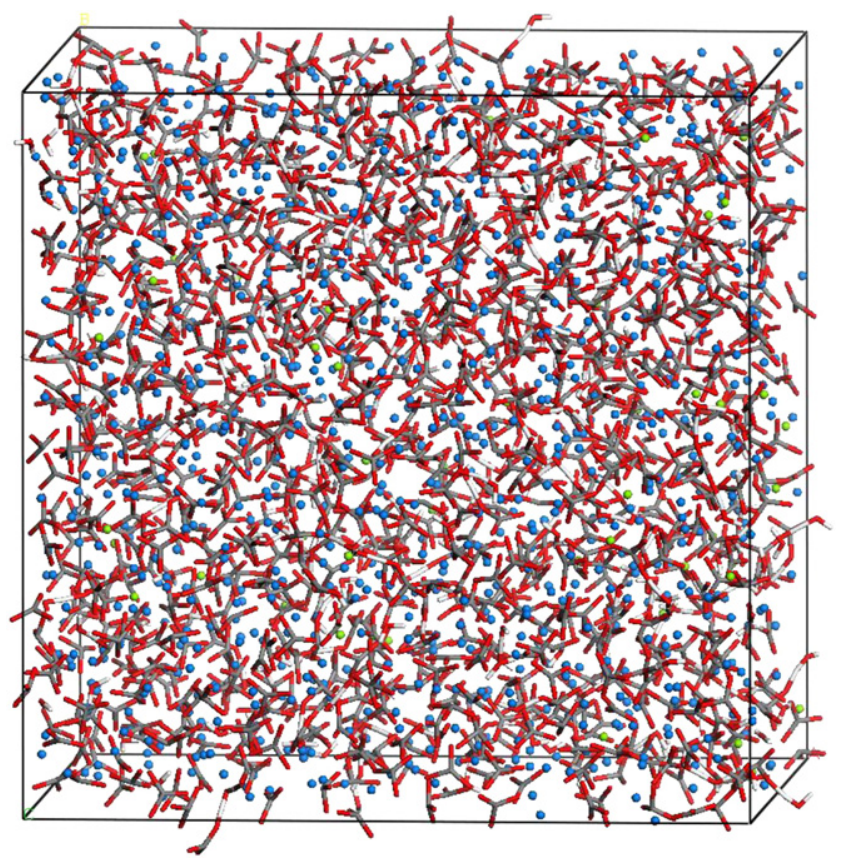

Fig. 2. EPSR model of Mg-stabilised ACC containing 5750 atoms with box length of $39.55 \AA$ (oxygen is red, carbon is grey, hydrogen is white, calcium is blue, magnesium is green). (For interpretation of the references to colour in this figure legend, the reader is referred to the web version of this article.)

molecules. These features of the model are in good agreement with the EXAFS results of Michel et al. [3] for ACC prepared by a similar method: $\mathrm{Ca}-\mathrm{O}$ coordination number of $6.7 \pm 1.7$ and peak distance of $2.41 \pm 0.02 \AA$. Due to the coordination of $\mathrm{Ca}$ to oxygen in $\mathrm{CO}_{3}$ and $\mathrm{H}_{2} \mathrm{O}$ molecules, there are consequently noticeable correlations of Ca... $\mathrm{C}$ and $\mathrm{Ca}$...H. The PDFs for Mg are similar to those for Ca, but they are not presented in detail because of the poor statistics due to the small number of $\mathrm{Mg}$ in the model.

The first peak at 3.3-4.5 ̊̊ in the Ca-Ca PDF (see Fig. 4) corresponds to two calcium ions which share bonds with a common oxygen, i.e. $\mathrm{Ca}-$ $\mathrm{O}-\mathrm{Ca}$. Fig. 5 shows these $\mathrm{Ca}-\mathrm{O}-\mathrm{Ca}$ configurations as single blue lines originating from and terminating at the positions of $\mathrm{Ca}$ ions. This feature

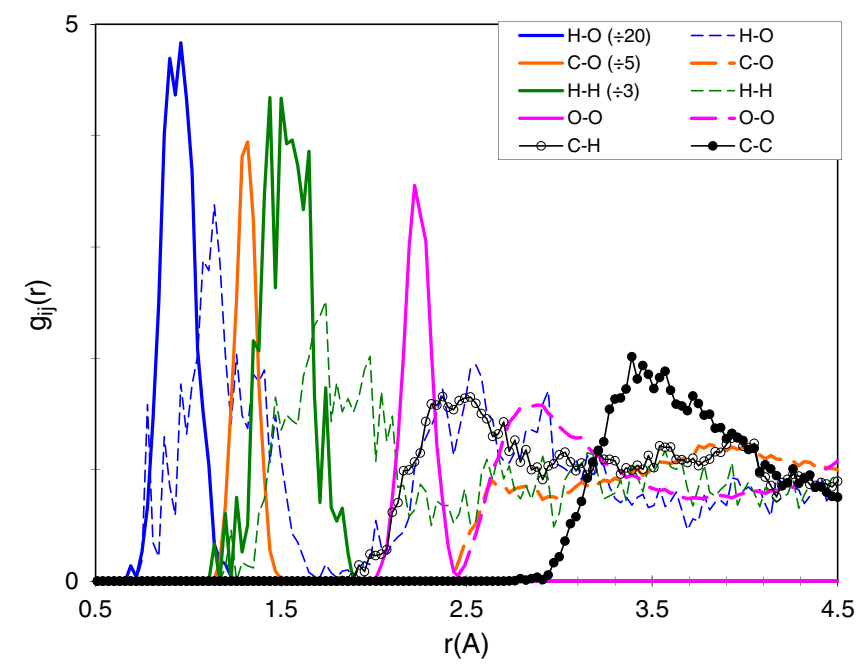

Fig. 3. Pair distribution functions (PDFs) $g_{i j}(r)$ for Mg-stabilised ACC from the EPSR model. Intra-molecular PDFs (solid lines) represent the internal structure of the molecules: $\mathrm{O}-\mathrm{H}$ and $\mathrm{H}-\mathrm{H}$ distances in $\mathrm{H}_{2} \mathrm{O}$, and $\mathrm{C}-\mathrm{O}$ and $\mathrm{O}-\mathrm{O}$ distances in $\mathrm{CO}_{3}$. Inter-molecular PDFs (dashed lines) show $\mathrm{H}$... H and $\mathrm{H}$... O correlations between $\mathrm{H}_{2} \mathrm{O}$ (light dashed), and C...O and $\mathrm{O} . . . \mathrm{O}$ correlations between all molecules (heavy dashed). 
Table 1

Inter-atomic correlations involving $\mathrm{CO}_{3}$ and $\mathrm{H}_{2} \mathrm{O}$ molecular units (distances shown in brackets are approximate, and the corresponding correlation is also shown in brackets).

\begin{tabular}{lll}
\hline Distance $(\AA)$ & Atoms types $\mathrm{i}-\mathrm{j}$ & Type of correlation between molecular units \\
\hline 0.93 and $(1.2)^{*}$ & $\mathrm{H}-\mathrm{O}$ & Intra and (inter) ${ }^{*} \mathrm{H}_{2} \mathrm{O}$ \\
1.32 & $\mathrm{C}-\mathrm{O}$ & Intra $\mathrm{CO}_{3}$ \\
1.56 and $(1.9)^{*}$ & $\mathrm{H}-\mathrm{H}$ & Intra and (inter) ${ }^{*} \mathrm{H}_{2} \mathrm{O}$ \\
2.22 & $\mathrm{O}-\mathrm{O}$ & Intra $\mathrm{CO}_{3}$ \\
$(2.4)$ & $\mathrm{C}-\mathrm{H}$ & Inter $\mathrm{CO}_{3}$ and $\mathrm{H}_{2} \mathrm{O}$ \\
$(2.8)$ & $\mathrm{O}-\mathrm{O}$ & Inter $\mathrm{CO}_{3}$ and $\mathrm{H}_{2} \mathrm{O}$ \\
$(3.3)$ & $\mathrm{C}-\mathrm{O}$ & Inter $\mathrm{CO}_{3}$ and $\mathrm{H}_{2} \mathrm{O}$ \\
$(3.5)$ & $\mathrm{C}-\mathrm{C}$ & Inter $\mathrm{CO}_{3}$ \\
\hline
\end{tabular}

* Denotes correlations involving hydrogen bonding as discussed in the text.

of the structure was previously referred to as the "Ca-rich network" [16], and Fig. 5 indicates that such a "Ca rich network" is homogeneously distributed throughout the present model. The grey surfaces around regions more than 3.3 A distant from Ca represent the structural feature which was previously referred to as "Ca-poor channels" [16]. Fig. 5 shows that there are only a few marginal volumes fitting this criterion. In the previous study [16] a less stringent limit of $4 \AA$ was used and the present model has no such volumes.

\section{Discussion}

This study uses both neutron and X-ray diffraction data as a more stringent test of simulation than previous studies (e.g. [16]). Note that the two techniques employed have different sensitivity to interatomic correlations, due to the different atomic scattering factors for neutrons and X-rays. In particular, neutrons are more sensitive to oxygen and hydrogen, whereas X-rays are more sensitive to calcium. The final level of agreement obtained is shown in Fig. 1. In terms of the structure factor $\mathrm{S}(\mathrm{Q})$, there is fair quantitative agreement for $\mathrm{Q}>4 \AA^{-1}$ corresponding to short range order, and fair qualitative agreement $1<\mathrm{Q}<4 \AA^{-1}$ corresponding to medium range order. In terms of the total pair distribution function $g(r)$, there is fair quantitative agreement in short range order up to $3 \AA$.

The EPSR method has been successful at incorporating well-defined $\mathrm{CO}_{3}$ and $\mathrm{H}_{2} \mathrm{O}$ molecular units with the expected intra-molecular correlations. The inter-molecular correlations (see Table 1 ) include $\mathrm{H}$... O and $\mathrm{O} . . . \mathrm{O}$ peaks due to hydrogen bonding of $\mathrm{H}_{2} \mathrm{O}$ molecules, although the peak distances are slightly shorter than expected for typical $\mathrm{H} . . . \mathrm{O}$

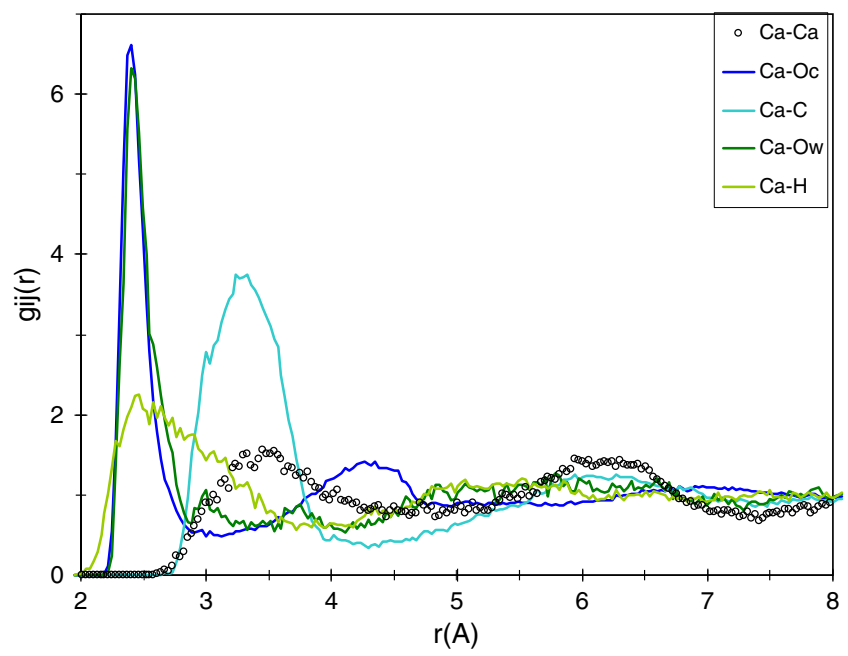

Fig. 4. Pair distribution functions (PDFs) $g_{i j}(r)$ for Mg-stabilised ACC from the EPSR model. PDFs involving calcium are shown (note Oc and Ow refer to oxygens in $\mathrm{CO}_{3}$ and $\mathrm{H}_{2} \mathrm{O}$ molecules respectively). hydrogen bond lengths of 1.6-2.0 $\AA . \mathrm{H}_{2} \mathrm{O}$ molecules are outnumbered 4 to 1 by $\mathrm{CO}_{3}$ molecules, so the presence of hydrogen bonding would suggest a tendency for $\mathrm{H}_{2} \mathrm{O}$ molecules to be found near to one another.

This is the first model to be reported for Mg-stabilised ACC, and the first model of any kind of ACC to be compared with experimental neutron diffraction data. The $\mathrm{Ca}-\mathrm{O}$ coordination is composed of relative contributions of $\mathrm{CO}_{3}$ and $\mathrm{H}_{2} \mathrm{O}$ of 6.8 and 0.6 respectively. These are in the ratio of 12:1. In comparison the available oxygens are 3 per $\mathrm{CO}_{3} \mathrm{~mol}-$ ecule and 1 per $\mathrm{H}_{2} \mathrm{O}$ molecule, and these molecules are in a ratio of $4: 1$. Thus, the available oxygen from $\mathrm{CO}_{3}$ and $\mathrm{H}_{2} \mathrm{O}$ molecules are in the ratio of $12: 1$, the same ratio as observed in the contributions to $\mathrm{Ca}-\mathrm{O}$ coordination. The average $\mathrm{Ca}$...C coordination number is 6.6 which is almost the same as the average number, 6.8 , of Ca bonds to oxygen in $\mathrm{CO}_{3}$ molecules. This means that on average each carbonate oxygen which is bonded to calcium is from a separate carbonate molecule. The number of Ca bonds to carbonate oxygens is 6.8 times the number of $\mathrm{Ca}$ in the model. Since the ratio of Ca to carbonate oxygen in the model is $1: 3$, this means that the number of carbonate oxygen bonds to $\mathrm{Ca}$ is 6.8 divided by 3 or 2.2 . So each $\mathrm{O}$ in a $\mathrm{CO}_{3}$ unit is typically bonded to 2 different $\mathrm{Ca}$ neighbours, i.e. $\mathrm{Ca}-\mathrm{O}-\mathrm{Ca}$ linkages are common.

The present EPSR model of Mg-ACC has Mg:Ca ratio of 0.05:0.95 and a water content of $\mathrm{n}=0.25$. This is a somewhat different composition to the previously reported RMC model of ACC, which had no Mg and $\mathrm{n}=1.0$ [16]. Nevertheless, it is interesting to compare the Ca distribution in these two models. The previously reported RMC model of ACC had a "Ca-rich network" (based on $\mathrm{Ca}-\mathrm{O}$ - Ca linkages), which was inhomogeneously distributed, and interspersed with significant volumes of "Ca-poor channels" (based on the limit of volumes more than $4 \AA$ A distant from Ca). The homogeneous Ca distribution in the present EPSR model of Mg-ACC fails to reproduce the inhomogeneous features in the previously reported RMC model of ACC.

In the present study, the proton content of the sample was reduced by using heat treatment. An alternative approach is to deuterate the sample by substituting protons for deuteriums, $\mathrm{D}$, which has the benefits of reducing incoherent and inelastic scattering, and providing scattering contrast due to the different neutron scattering length for D compared to protons. In the present study, an unsuccessful attempt was made to produce a deuterated ACC sample, but the authors plan to attempt this again in future work.

\section{Conclusions}

Preparation of Mg-stabilised ACC has enabled the first neutron diffraction measurement of Mg-stabilised ACC. The EPSR modelling method has used this neutron diffraction data, together with X-ray diffraction data, to build a model of Mg-stabilised ACC, which is in fair agreement with the experimental diffraction data. The model contains the expected molecular units of $\mathrm{CO}_{3}$ and $\mathrm{H}_{2} \mathrm{O}$ with some hydrogen bonding of $\mathrm{H}_{2} \mathrm{O}$. Calcium has an average coordination of 7.4, with a peak distance of $2.40 \AA$, in agreement with previously reported EXAFS results [3]. The Ca coordination is comprised of approximately 6.7 oxygens from separate $\mathrm{CO}_{3}$ molecules, and $\mathrm{Ca}-\mathrm{O}-\mathrm{Ca}$ linkages are prevalent throughout the structure. The Ca distribution is homogeneous and does not show the inhomogeneous characteristics which were previously reported for an RMC model of ACC [16].

\section{Acknowledgements}

We gratefully acknowledge O.L.G. Alderman, University of Warwick, for assistance with the EPSR method. Beamtime awards from ISIS and ELETTRA facilities are gratefully acknowledged. Funding for JDRB and LGB from the Marie Curie EU-FP6 Mineral Nucleation and Growth Kinetics (MIN-GRO) Research and Training Network under contract MRTNCT2006-035488 is gratefully acknowledged. 


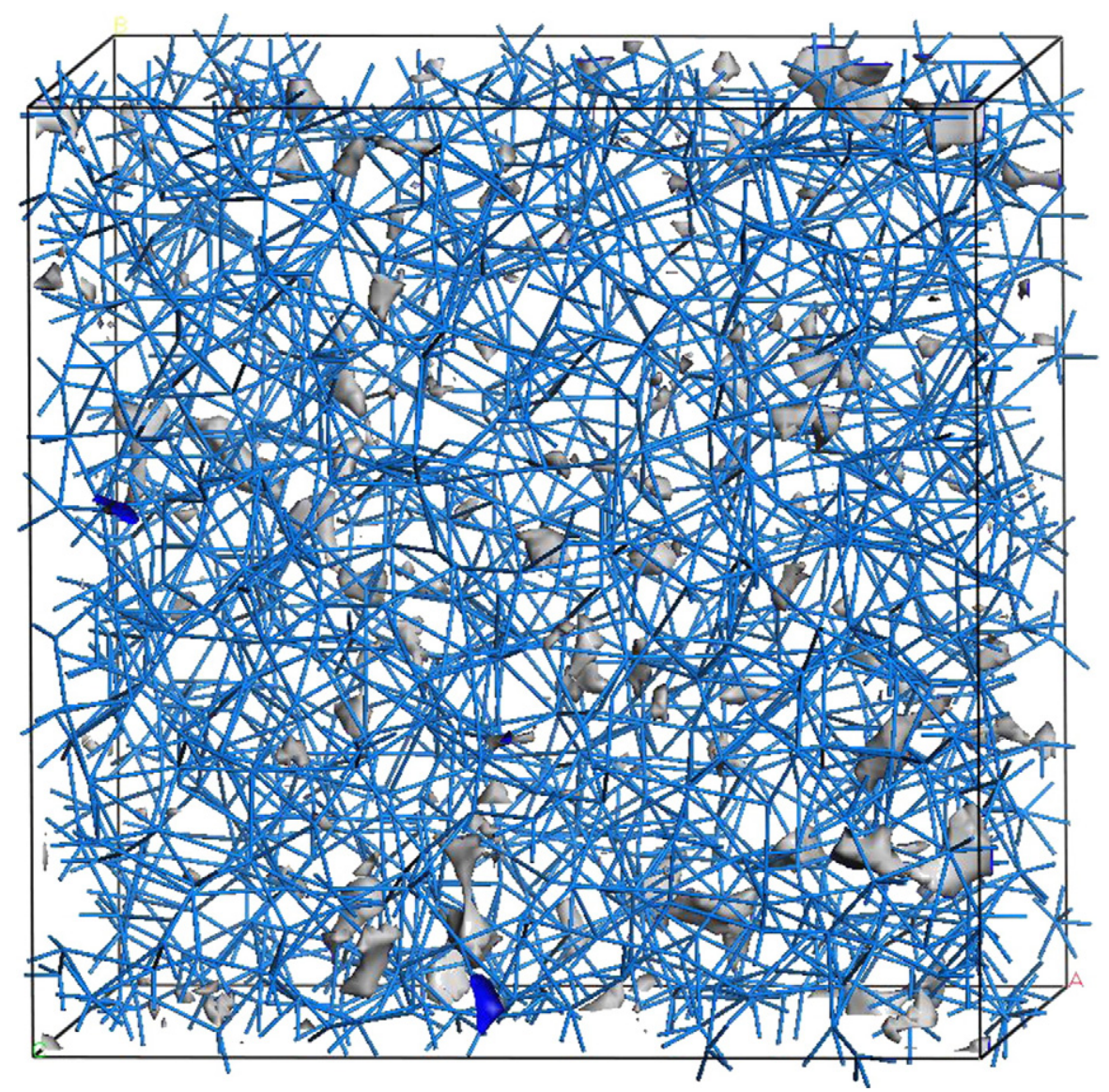

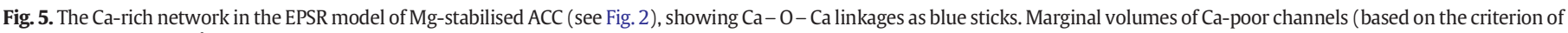

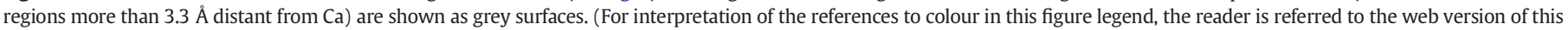
article.)

\section{References}

[1] L. Addadi, S. Raz, S. Weiner, Adv. Mater. 15 (2003) 959.

[2] C. Combes, C. Rey, Acta Biomat. 6 (2010) 3362.

[3] F.M. Michel, J. MacDonald, J. Feng, B.L. Phillips, L. Ehm, C. Tarabrella, J.B. Parise, R.J. Reeder, Chem. Mater. 20 (2008) 4720.

[4] A.V. Radha, T.Z. Forbes, C.E. Killian, P.U.P.A. Gilbert, A. Navrotskya, Proc. Nat. Acad. Sci 107 (2010) 16438.

[5] K. Kojima, A. Kawanobe, T. Yasue, Y. Arai, J. Cer. Soc. Jpn. 101 (1993) 1145.

[6] N. Koga, Y. Nakagoe, H. Tanaka, Thermochim. Acta 318 (1998) 239.

[7] P. Raiteri, J.D. Gale, J. Am. Chem. Soc. 132 (2010) 17623.

[8] J.D. Rodriguez-Blanco, S. Shaw, L.G. Benning, Nanoscale 3 (2011) 265

[9] J.D. Rodriguez-Blanco, P. Bots, T. Roncal-Herrero, S. Shaw, L.G. Benning, J. Alloys Comp. 536 (2012) S477.

[10] E. Loste, R.J. Park, J. Warren, F.C. Meldrum, Adv. Funct. Mater. 14 (2004) 1211.

[11] J. Johnson, H.E. Merwin, E.D. Williamson, Am. J. Sci. 111 (1916) 33.

[12] F.A. Andersen, L. Brecevic, Acta Chem. Scand. 45 (1991) 1018.

13] D. Wang, L.M. Hamm, R.J. Bodnar, P.M. Dove, J. Raman, Spectrosc. 43 (2012) 543.

[14] C. Günther, A. Becker, G. Wolf, M. Epple, Z. Anorg, Allg. Chem. 631 (2005) 2830.

[15] H.E. Fischer, A.C. Barnes, P.S. Salmon, Rep. Prog. Phys. 69 (2006) 233.
[16] A.L. Goodwin, F.M. Michel, B.L. Phillips, D.A. Keen, M.T. Dove, R.J. Reeder, Chem. Mater. 22 (2010) 3197

[17] J.W. Singer, A.Ö. Yazaydin, R.J. Kirkpatrick, G.M. Bowers, Chem. Mater. 24 (1828) 2012.

[18] J. Jiang, M.R. Gau, Y.H. Qiu, S.H. Yu, Nanoscale 2 (2010) 2358.

[19] J. Ihli, Y.Y. Kim, E.H. Noel, F.C. Meldrum, Adv. Funct. Mater. 23 (2012) 1575.

[20] A.V. Radha, A. Fernandez-Martinez, Y. Huc, Y.-S. Jun, G.A. Waychunas, A. Navrotsky, Geoch. Cosmoch. Acta 90 (2012) 83.

[21] D. Di Tommaso, N.H. De Leeuw, Phys. Chem. Chem. Phys 12 (2010) 894

[22] A.K. Soper, Chem. Phys. 202 (1996) 295.

[23] A.K. Soper, J. Mol. Liquids 78 (1998) 179

[24] R.L. McGreevy, L Pusztai, Mol. Simulation 1 (1988) 359.

[25] J.D. Rodriguez-Blanco, S. Shaw, L.G. Benning, Mineral. Magazine 72 (2008) 283

[26] ICANS-XI International Collaboration on Advanced Neutron Sources, in: A.K. Soper, M. Misawa, et al., (Eds.), National Laboratory for High Energy Physics, KEK: KEK, Tsukuba, Japan, 1990, p. 809.

[27] A.K. Soper, Rutherford Appleton Laboratory Technical Report, RAL-TR-2011-013, 2011.

[28] A. Lausi, E. Busetto, M. Leoni, P. Scardi, Synchrotron Radiation in Natural Science 5 (2006) 100.

[29] A.K. Soper, Rutherford Appleton Laboratory Technical Report, RAL-TR-2011-012, 2011.

[30] T. Hassinen, M. Peräkylä, J. Comput. Chem. 22 (2001) 1229. 